\title{
Status of IGS Reprocessing Activities at GFZ
}

\author{
Benjamin Männel, Andre Brandt, Markus Bradke, Pierre Sakic, \\ Andreas Brack, and Thomas Nischan
}

\begin{abstract}
Based on a large network of continuously operated GNSS tracking stations the International GNSS Service (IGS) has a valuable contribution for the realization of the International Terrestrial Reference System (ITRS). In order to contribute to its next realization, the IGS is preparing for a new reprocessing of the GNSS data from 1994 to 2020 including GPS, GLONASS, and - for the first time - Galileo. A first test campaign including single- and multi-system solutions for 2017 and 2018 was performed to derive consistent transmitter phase center corrections for all systems. Preliminary results of the test solutions derived at GFZ show well determined orbits with overlaps of $28 \mathrm{~mm}$ for GPS, $67 \mathrm{~mm}$ for GLONASS, and $40 \mathrm{~mm}$ for Galileo and an overall RMS of satellite laser ranging residuals for Galileo of $58 \mathrm{~mm}$. Using multi-GNSS antenna calibrations (including also E5a and E5b calibrations) horizontal coordinate differences are almost zero between a GPS+GLONASS and a Galileo-only solutions. Due to the mixture of estimated (GPS, GLONASS) and measured (Galileo) transmitter phase center offsets a scale difference of $1.16 \pm 0.27 \mathrm{ppb}$ is found between both solutions which agrees nicely to results derived by other analysis centers.
\end{abstract}

\section{Keywords}

GNSS · Orbit determination · Reprocessing · Terrestrial Reference Frame

\section{Introduction}

To provide the best possible GNSS solution for the realization of the International Terrestrial Reference System, the Analysis Centers (ACs) of the International GNSS Service (IGS, Johnston et al. 2017) are preparing for a full reprocessing of GNSS data from 1994 to 2020 . Like the previous efforts (repro1 and repro2) the upcoming reprocessing will provide a fully consistent set of orbits, station coordinates and Earth rotation parameters derived with the best and most consistent models available. It is well

B. Männel $(\bowtie) \cdot$ A. Brandt · M. Bradke · P. Sakic · A. Brack · T. Nischan

Helmholtz Centre Potsdam - German Research Centre for

Geosciences, Potsdam, Germany

e-mail: benjamin.maennel@gfz-potsdam.de known that in terms of reference frame parameters the most critical issues for GNSS are, firstly, the transmitter phase center offsets (which are highly correlated with the terrestrial scale, e.g., Zhu et al. 2003) and, secondly, the modeling of the solar radiation pressure on the orbits (main reason for draconitic period in geocenter results, e.g., Meindl et al. 2013). While trying to reduce or to solve both issues several additional topics have to be considered like the 13.63/13.66 day signal in GNSS time series (see for example Ray et al. 2013) or remaining modeling inconsistencies compared to other space geodetic techniques. Compared to the last reprocessing, new satellite systems like Galileo and BeiDou became almost fully operational. As their signals were tracked by an increasing number of IGS stations during the past years, the set of considered systems has to be redefined from GPS+GLONASS in repro2 to an up-to-date multi-GNSS solution. 
Fig. 1 Stability of selected IGS stations (according to IGS-ACS-1235 mail category c1 to $\mathrm{c} 4$ as well as GFZ stations in other categories): height repeatability derived by GPS-only PPP processing between 1999.0 and 2018.0

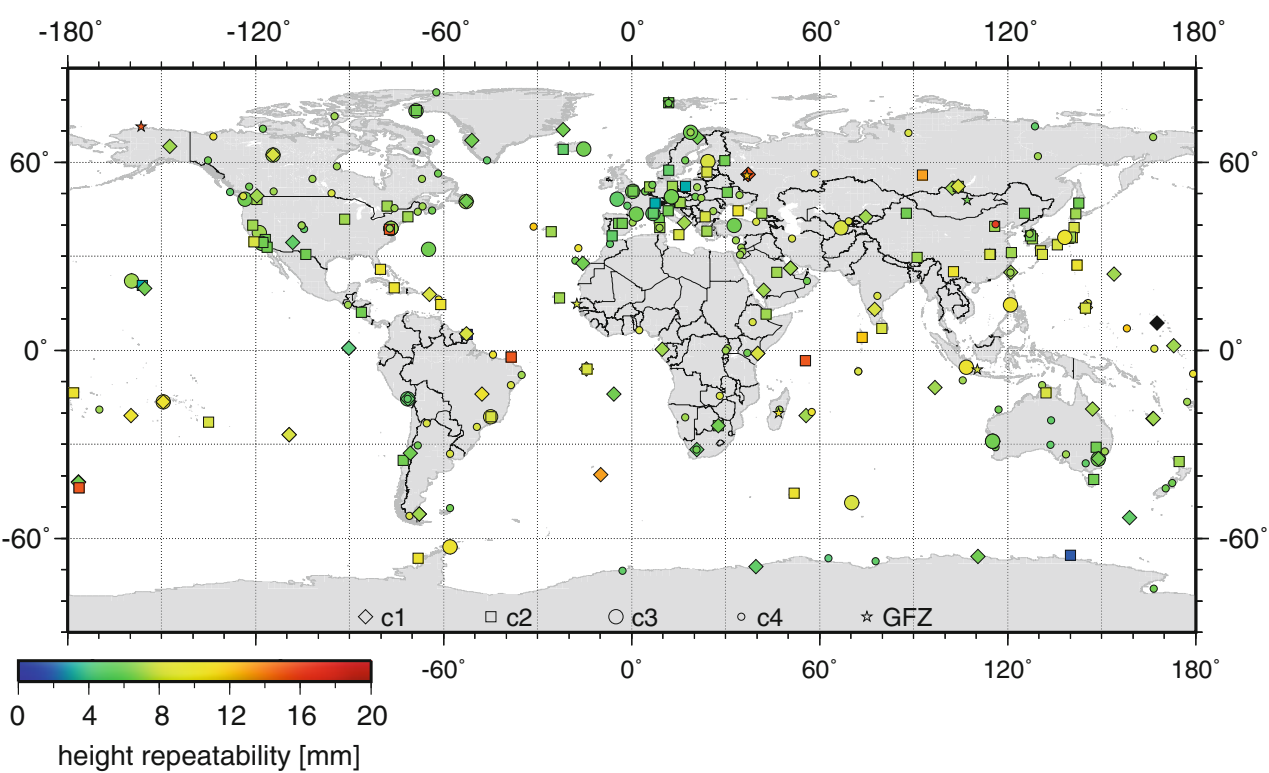

During the IGS Analysis Workshop 2019 held in Potsdam, Germany, the IGS ACs agreed to strive for an combined GPS (G), GLONASS (R), and Galileo (E) solution in the upcoming repro3. However, to avoid systematic distortions, so far missing, receiver antenna corrections for the Galileo signals E5a, E5b, and E6 and the GPS L5 frequency as well as consistent transmitter phase center offsets (PCOs) are required (see e.g. Schmid et al. 2016). Whereas the first issue was solved for many antenna types used in the IGS as Geo++ provided robot-based calibrations for these signals it was agreed to solve the second issue by setting up a test campaign. This campaign includes multi- and singlesystem solutions (if possible GRE, GR, G, R, and E) for 2017 and 2018 which will be used to derive phase center offsets for GPS and GLONASS based on the Galileo offsets which are known thanks to published chamber calibrations (GSA 2017). As these Galileo PCOs are measured - and not estimated from observations itself - they are independent of the terrestrial scale which has to be fixed to the ITRF scale otherwise (Schmid et al. 2007). Therefore, an independent GNSS scale will become available if the final repro3 could be performed with this consistent set of re-estimated and calibrated PCOs. It was also agreed to run a second test campaign using the final repro3 setup including the station selection as benchmark test before starting the processing tasks.

This paper summarizes the current reprocessing status at GFZ during the first test campaign and highlights preliminary outcomes. Section 2 describes investigations regarding station selection and testing some models. Initial results based on the different GFZ solutions in the first test campaign will be presented in Sect. 3. Section 4 provides an outlook to the upcoming tasks.

\section{Data and Processing}

This section discusses the processed data, the station network, and the selected models for the test campaign but also for the final reprocessing.

\subsection{Data Selection}

The station selection process is based on the pre-selection and station classification which was provided to the Analysis Centres by Paul Rebischung via the IGS AC mailing list (IGS-ACS-1235). ${ }^{1}$ According to software and time capabilities we will process stations listed in Categories 1 (revised set of IGS14 core stations), 2 (stations with local ties to other techniques), 3 (redundant local tie stations), and 4 (remaining IGS14 stations) as well as IGS stations operated by GFZ placed in lower categories. In order to assess this selection we re-imported the whole data set into our archive with dedicated checks for formal correctness and consistency with the provided site logs. In addition, we processed the GPS observations from all selected IGS stations using the EPOS.P8 software in PPP mode to identify the stations temporal behavior. ${ }^{2}$ The processing was done based on orbit and clock products derived within a GFZ internal reprocessing effort which we carried out in 2018 to derive consistent products in the IGS14 frame. Figure 1 shows

\footnotetext{
${ }^{1}$ Available also at http://acc.igs.org/repro3/repro3, accessed January 2020.

${ }^{2}$ Stations provided by other networks, like SONEL (3), OAFA (1), GREF (1), EPN (4), NGS (6), UNAVCO (2), are not considered for this initial assessment but will be processed in the final reprocessing.
} 
the derived height coordinate repeatability for each station with the symbol identifying the station's category. Overall, 325 stations are contained while the average repeatability is $7.5 \pm 1.9 \mathrm{~mm}$ (median is $7.2 \mathrm{~mm}$ ). The GFZ contribution to the first test campaign was, however, processed using the station selection used in GFZ's operational processing (IGS final line, 220 stations) supported by additional 30 IGS stations selected to achieve a basic coverage for Galileo also in early 2017. However, the number of selected Galileo sites was still rather low for an independent Galileo-only solution. For January 1st, 2017 the number of stations was 222/137/68 for GPS, GLONASS, and Galileo while rising to $210 / 145 / 124$ for Dec. 31st, 2018 due to ongoing station upgrades within the IGS tracking network. With respect to the number of Galileo satellites it might be interesting to know that the number of satellites increased from 13 to 22 within the same time span. ${ }^{3}$

\subsection{Processing of the First Test Campaign}

Table 1 provides the processing strategy applied for the test campaign. The same parametrization can be expected for the final reprocessing. However, the orbit parametrization might be modified for some satellite blocks as tests regarding the optimal setup are performed currently. In general, the settings follow the IERS Conventions 2010 (Petit and Luzum 2010) and the repro2 standards. Using the EPOS.P8 software GFZ provided four solutions (GRE, GR, $\mathrm{G}$, and $\mathrm{E}$ ).

\subsection{Updating Models for Repro 3}

According to the discussions between the IGS ACs and the IERS, several models have to be updated for the final reprocessing compared to Table 1 . For computing the rotational deformation (pole tide) the linear mean pole will be used as adopted by the IERS in 2018. Regarding the gravity field, a static gravity field up to degree and order 12 was used whereas a time-variable gravity field should be used in the reprocessing. The ocean tides and ocean loading model will be updated to a more recent FES2014b model (Carrere et al. 2016). In order to consider high-frequency variations in Earth orientation parameters (EOP) it was agreed to use the model provided by Desai and Sibois (2016) instead of the model provided in the IERS Conventions.

\footnotetext{
${ }^{3}$ The four satellites launched in July 2018 are not included as they were not operational before January 2019.
}

Table 1 Summary of estimation and processing strategy (repro3 test campaign); time span 2017.0-2019.0; the used ANTEX was provided by A. Villiger and the IGS ANTEX working group (IGSACS-1233 mail)

\begin{tabular}{|c|c|}
\hline \multicolumn{2}{|c|}{ Modeling and a-priori information } \\
\hline Observations & $\begin{array}{l}\text { Ionosphere-free linear combination } \\
\text { formed by undifferenced GPS } \\
\text { observations }\end{array}$ \\
\hline Tropospheric correction & $\begin{array}{l}\text { GPT2 meteo values mapped with VMF1 } \\
\text { (Böhm et al. 2006) }\end{array}$ \\
\hline Ionospheric correction & $\begin{array}{l}\text { First order effect considered with } \\
\text { ionosphere-free linear combination, } \\
\text { second order effect corrected using the } \\
\text { International Magnetic Reference Field } \\
\text { (11th realization, Finlay et al. 2010) }\end{array}$ \\
\hline GNSS phase center & $\begin{array}{l}\text { Dedicated multi-GNSS ANTEX applied } \\
\text { (igsR3_2057.atx) }\end{array}$ \\
\hline Clock datum & $\begin{array}{l}\text { Zero-mean condition for satellites and } \\
\text { selected stations }\end{array}$ \\
\hline Gravity potential & $\begin{array}{l}\text { EGM2008 up to degree and order } 12 \\
\text { (Pavlis et al. 2012) }\end{array}$ \\
\hline Solid Earth tides & $\begin{array}{l}\text { According to IERS } 2010 \text { Conventions } \\
\text { (Petit and Luzum 2010) }\end{array}$ \\
\hline Permanent tide & Conventional tide free \\
\hline Ocean tide model & FES2004 (Lyard et al. 2006) \\
\hline Ocean loading & FES2004 (Lyard et al. 2006) \\
\hline Atmospheric loading & $\begin{array}{l}\text { Tidal: } S_{1} \text { and } S_{2} \text { corrections (Ray and } \\
\text { Ponte } 2003 \text { ) }\end{array}$ \\
\hline High-frequent EOP model & $\begin{array}{l}\text { Desai-Sibois model (Desai and Sibois } \\
\text { 2016) }\end{array}$ \\
\hline Mean pole tide & $\begin{array}{l}\text { Linear mean pole as adopted by the } \\
\text { IERS in } 2018\end{array}$ \\
\hline \multicolumn{2}{|l|}{ Parametrization } \\
\hline Station coordinates & $\begin{array}{l}\text { No-net-rotation w.r.t. IGS14 } \\
\text { (Rebischung and Schmid 2016) }\end{array}$ \\
\hline Troposphere & $\begin{array}{l}\text { Zenith wet delays for } 0.5 \mathrm{~h} \text { intervals; } \\
\text { two gradient pairs per station and day }\end{array}$ \\
\hline GPS orbit modeling & $\begin{array}{l}\text { Six initial conditions + nine ECOM } 2 \\
\text { parameters, pulses at } 12 \mathrm{~h}\end{array}$ \\
\hline Earth rotation & $\begin{array}{l}\text { Rotation pole coordinates, pole-rates } \\
\text { and LOD for } 24 \mathrm{~h} \text { intervals, UT } 1 \text { tightly } \\
\text { constrained to a priori Bulletin A }\end{array}$ \\
\hline Receiver clock & $\begin{array}{l}\text { Pre-eliminated every epoch, ISB per } \\
\text { station for Galileo, per station and } \\
\text { satellite for GLONASS }\end{array}$ \\
\hline Satellite clocks & Epoch-wise estimated \\
\hline GNSS ambiguities & Ambiguity fixing for GPS and Galileo \\
\hline Antenna Phase Center & $\begin{array}{l}\text { Estimated for GPS, GLONASS, and } \\
\text { Galileo but tightly constrained to values } \\
\text { given in ANTEX }\end{array}$ \\
\hline
\end{tabular}

\section{$3 \quad$ Initial Results}

Within this section initial results derived within the test campaign will be discussed with respect to the derived orbits and stations coordinates. Figure 2 shows the orbit misclosures (orbit overlap error) for all satellites processed in 


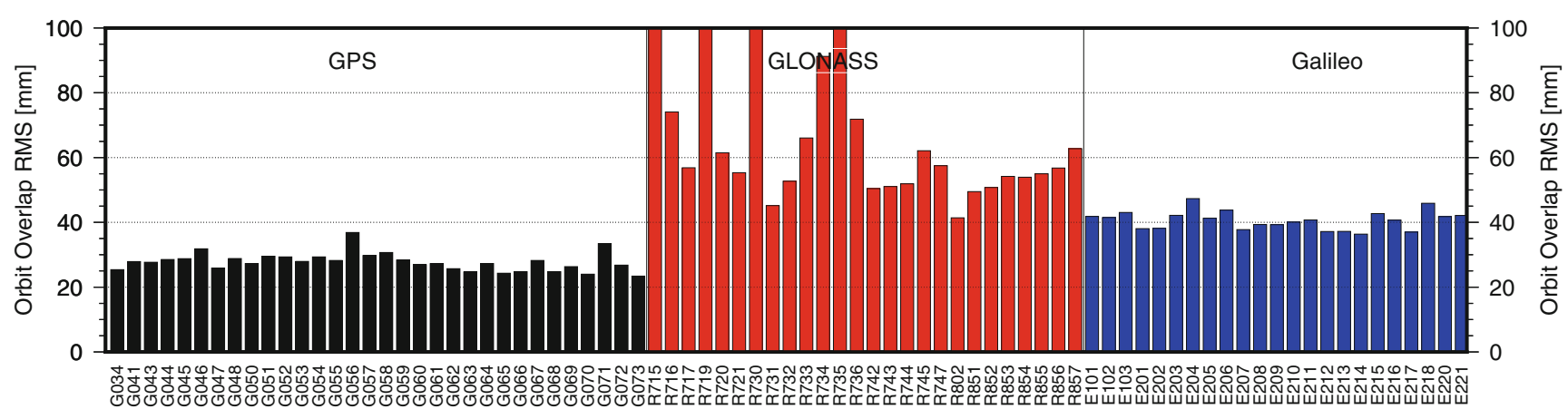

Fig. 2 Orbit overlaps errors; daily overlap RMS averaged for time span 2017.0-2019.0

Table 2 Orbit overlaps: average and standard deviation over all satellites and weeks; time span 2017.0-2019.0; unit: mm

\begin{tabular}{l|l|l|l}
\hline Solution & GPS & GLONASS & Galileo \\
\hline Full sol. (GRE) & $27.8 \pm 2.9$ & $67.6 \pm 26.3$ & $40.5 \pm 2.9$ \\
\hline GPS+GLO (GR) & $28.5 \pm 2.8$ & $65.4 \pm 27.4$ & - \\
\hline GPS (G) & $28.4 \pm 2.8$ & - & - \\
\hline GAL (E) & - & - & $40.5 \pm 3.6$ \\
\hline
\end{tabular}

Table 3 Orbit overlaps: large GLONASS values; time span 2017.0 2019.0; as reference the overlaps provided in Table 1 of Dach et al. (2019) are given; unit: $\mathrm{mm}$

\begin{tabular}{l|l|l|l|l}
\hline SVN & PRN & GRE & GR & Dach et al. (2019) \\
\hline R715 & R14 & 157.2 & 157.9 & - \\
\hline R719 & R20 & 114.3 & 114.0 & - \\
\hline R730 & R01 & 103.5 & 97.2 & 103 \\
\hline R734 & R05 & 91.2 & 89.7 & 112 \\
\hline R735 & R24 & 110.4 & 111.0 & 118 \\
\hline
\end{tabular}

the full solution (GRE). The overlaps are computed for $2 \mathrm{~h}$ each while estimating transformation parameters between the two orbit solutions. An averaged RMS of $28 \mathrm{~mm}$ is achieved for the GPS satellites. As shown in Table 2 the RMS is independent of the solution type (GRE, GR, or G) for GPS with differences of $1 \mathrm{~mm}$. It is obvious, that the GPS orbits are not downgraded in terms of overlap errors by adding other systems to the solutions. For GLONASS a larger mean RMS of $67 \mathrm{~mm}$ is observed while five satellites exceed $90 \mathrm{~mm}$ overlap error (see Table 3 ). As shown in this table, Dach et al. (2019) reported similarly large overlaps for two of the three satellites (R715 and R719 are not contained in Table 1 of Dach et al. (2019)). Without these satellites the remaining average is $57.8 \mathrm{~mm}$. Galileo orbit overlaps are in general larger compared to GPS mis-closures. Without large variations between the satellites an averaged RMS of $40 \mathrm{~mm}$ is determined for Galileo which is also achieved by the Galileo-only solution.

In order to further asses the satellite orbits a validation based on satellite laser ranging (SLR) was performed. While fixing the SLR telescope positions to their ITRF2014 coordi- nates (Altamimi et al. 2016) and estimating no other parameters, the derived residuals (i.e., the differences between observed and computed ranges) provide insights into the absolute orbit accuracy. The number of SLR observations varies between 350 normal points (E217 and E218) and more than 17,000 (R802, R853). On average 5,230 normal points are collected per satellite within the 2 years. During the processing $3.6 \%$ and $2.1 \%$ of the observations where excluded as outliers for GLONASS and Galileo, respectively. Figure 3 shows the derived statistics. The determined biases, i.e., mean values over all residuals, reach up to $25 \mathrm{~mm}$ for GLONASS with some large variations between the satellites. For R856 with only 742 observations a larger bias of $44 \mathrm{~mm}$ is determined. In general, remaining biases indicate systematics contained in the orbits (or applied sensor offsets). In the current solution positive biases are visible for most of the GLONASS satellites which needs further investigations. The biases for Galileo are small (few millimeters) but also mostly positive for the whole constellation. The larger bias of $-13 \mathrm{~mm}$ for E218 might be related to the low number of 350 SLR observations available for this satellite launched in December 2017. The standard deviation of all SLR residuals reaches $91.5 \pm 13.3 \mathrm{~mm}$ for GLONASS and $58.3 \pm 8.7 \mathrm{~mm}$ for Galileo.

With respect to the different solutions a comparison of the station coordinates is very important. In theory, the estimated station coordinate should be independent of the processed GNSS. However, it was shown for example by Villiger et al. (2019) that one has to expect significant coordinate differences between system-specific solutions. These differences are mostly related to the considered antenna corrections for transmitter and receiver. As stated earlier, transmitter PCOs are either estimated in a global adjustment or - as for Galileo - chamber calibrated. In addition, robot-calibrations of receiving antennas were not available for several GNSS signals so far. Figure 4 shows the mean differences (and standard deviation) in North, East, and height coordinates derived in a combined (GR) and a Galileo-only solution using the provided multi-GNSS antenna corrections. It has to 


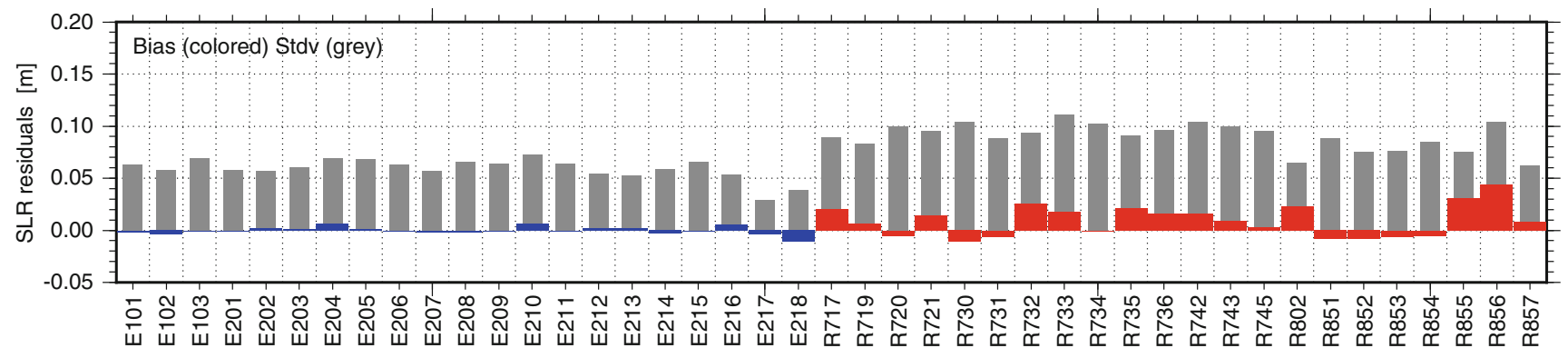

Fig. 3 SLR residuals: mean and standard deviation for time span 2017.0-2019.0
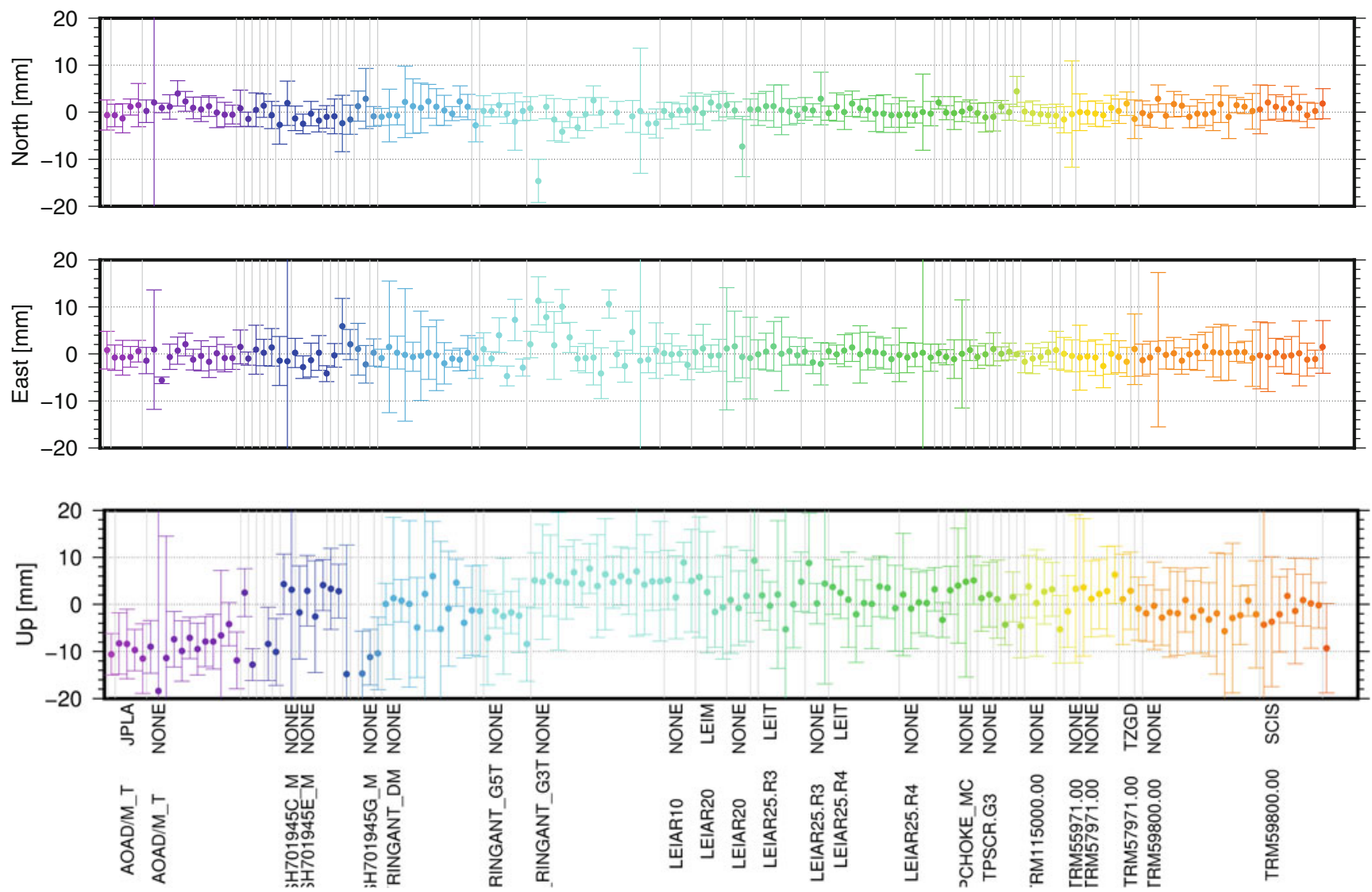

Fig. 4 Coordinate differences: GR-E mean and standard deviation for time span 2017.0-2019.0; from top to bottom: North, East, Up; sorted and color-coded by antenna types; antenna names are provided for

be mentioned that a seven parameter Helmert transformation was applied to determine also global systematics. The differences are sorted according to the antenna type of each station. However, some stations included in the processing are equipped with antennas having only L1/L2 calibrations (like the AOAD antennas). For these antennas larger height differences can be observed. In North and East direction overall no offset is visible with differences clearly below $5 \mathrm{~mm}$. Larger differences are visible only for stations equipped with the JAVRINGANT_G3T and JAVRINGANT_G5T antennas where some stations show differences of $10 \mathrm{~mm}$ in East direction (two stations showed also differences larger than types with at least three results, in addition a seven parameter Helmert transformation was applied

$20 \mathrm{~mm}$ in the North direction). Overall the coordinate differences agree well to differences computed from the test solutions provided for example by CODE and TU Graz. The height component shows, as expected, larger standard deviations but almost no significant offsets between the GR and the Galileo solution except for antennas with only L1/L2 calibrations which show differences of around $-10 \mathrm{~mm}$. Instead of comparing height differences, Fig. 5 shows the scale estimated as part of a Helmert transformation between the GR and the E solution (E-GR). Over the assessed 2 years, a scale difference of $1.16 \pm 0.27 \mathrm{ppb}$ was found. Due to the lower number of stations in the Galileo-only solution the 


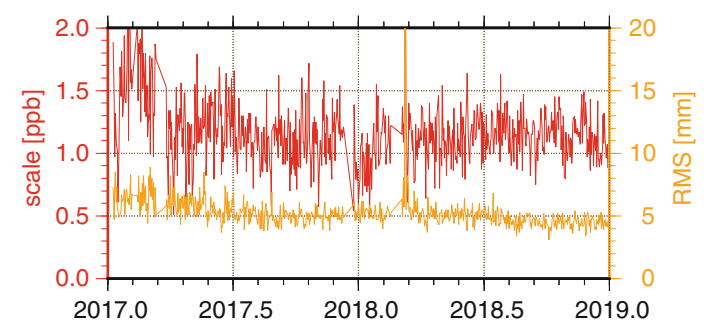

Fig. 5 Scale and RMS of the transformation between GR and E solution for time span 2017.0-2019.0

variation and also the RMS of the transformation is larger in the first half of 2017 compared to the following period. However, probably related to the lower number of Galileo satellites a somehow larger scale is derived for the first months in 2017. Again, the derived scale agrees well to the scale estimated between the solutions provided for example by CODE $(1.10 \pm 0.21 \mathrm{ppb})$ or by ESA $(1.09 \pm 0.18 \mathrm{ppb})$.

\section{$4 \quad$ Summary and Outlook}

The presented repro3 test campaign was performed at GFZ as contribution to the re-determination of transmitter phase center offsets for GPS and GLONASS in preparation for the final reprocessing. The current setup for this reprocessing is a three-system solution (GPS, GLONASS, Galileo) while some models like the time-variable gravity field are still in discussion between the IGS ACs and the IERS. The preliminary results show acceptable overlap errors for the individual satellites with on average $28 \mathrm{~mm}, 67 \mathrm{~mm}$ and $40 \mathrm{~mm}$ for GPS, GLONASS, and Galileo. An SLR orbit validation revealed also good orbit quality without significant biases for the Galileo satellites. Comparing the derived station coordinates a good agreement between the GR- and the Galileo-only solution can be found in the horizontal components with a scale difference of around $1.1 \mathrm{ppb}$. According to the reprocessing schedule, a second test campaign will be performed after final decisions on the models. In addition, a few open questions have to be addressed like the reason for large orbit overlap errors for some GLONASS satellites or the coordinate difference for some stations equipped with JAVRINGANT_G3T and JAVRINGANT_G5T antennas.

\section{References}

Altamimi Z, Rebischung P, Métivier L, Collilieux X (2016) ITRF2014: a new release of the International Terrestrial Reference Frame modeling non-linear station motions. J Geophys Res 121:6109-6131. https://doi.org/10.1002/2016JB013098

Böhm J, Werl B, Schuh H (2006) Troposphere mapping functions for GPS and VLBI from European Centre for medium-range weather forecasts operational analysis data. J Geophy Res 111(B2):B02406. https://doi.org/10.1029/2005JB003629

Carrere L, Lyard F, Cancet M, Guillot A, Picot N (2016) FES 2014, a new tidal model - validation results and perspectives for improvements. In: Presentation to ESA living planet conference, Prague 2016

Dach R, Susnik A, Grahsl A, Villiger A, Schaer S, Arnold D, Prange L, Jäggi A (2019) Improving GLONASS orbit quality by re-estimating satellite antenna offsets. Adv Space Res 63(12):3835-3847. https:// doi.org/10.1016/j.asr.2019.02.031

Desai SD, Sibois AE (2016) Evaluating predicted diurnal and semidiurnal tidal variations in polar motion with GPS-based observations. J Geophys Res Solid Earth 121(7):5237-5256. https://doi.org/10. 1002/2016JB013125

Finlay CC, Maus S, Beggan CD, Bondar TN, Chambodut A, Chernova TA, Chulliat A, Golovkov VP, Hamilton B, Hamoudi M, Holme R, Hulot G, Kuang W, Langlais B, Lesur V, Lowes FJ, Lühr H, Macmillan S, Mandea M, McLean S, Manoj C, Menvielle M, Michaelis I, Olsen N, Rauberg J, Rother M, Sabaka TJ, Tangborn A, Toffner-Clausen L, Thebault E, Thomson AWP, Wardinski I, Wei Z, Zvereva TI (2010) International geomagnetic reference field: the eleventh generation. Geophys J Int 183(3):1216-1230. https://doi. org/10.1111/j.1365-246X.2010.04804.x

GSA (2017) Galileo satellite metadata. https://www.gsc-europa.eu/ support-to-developers/galileo-satellite-metadata. Accessed 19 Aug 2019

Johnston G, Riddell A, Hausler G (2017) The international GNSS service. Springer International Publishing, Cham, pp 967-982. https:// doi.org/10.1007/978-3-319-42928-1

Lyard F, Lefevre F, Letellier T, Francis O (2006) Modelling the global ocean tides: modern insights from FES2004. Ocean Dyn 56(56):394-415. https://doi.org/10.1007/s10236-006-0086-x

Meindl M, Beutler G, Thaller D, Dach R, Jäggi A (2013) Geocenter coordinates estimated from GNSS data as viewed by perturbation theory. Adv Space Res 51:1047-1064. https://doi.org/10.1016/j.asr. 2012.10.026

Pavlis NK, Holmes SA, Kenyon SC, Factor JK (2012) The development and evaluation of the Earth Gravitational Model 2008 (EGM2008). J Geophys Res Solid Earth 117(B4). https://doi.org/10. 1029/2011JB008916

Petit G, Luzum B (2010) IERS conventions (2010). IERS Technical Note 36. Verlag des Bundesamts für Kartographie und Geodäsie, Frankfurt am Main, iSBN 3-89888-989-6

Ray R, Ponte R (2003) Barometric tides from ECMWF operational analyses. Ann Geophys 21(8):1897-1910

Ray J, Griffiths J, Collilieux X, Rebischung P (2013) Subseasonal GNSS positioning errors. Geophys Res Lett 40(22):5854-5860. https://doi.org/10.1002/2013GL058160

Rebischung P, Schmid R (2016) IGS14/igs14.atx: a new framework for the IGS products. In: Presentation to AGU fall conference, San Francisco, 2016

Schmid R, Steigenberger P, Gendt G, Ge M, Rothacher M (2007) Generation of a consistent absolute phase center correction model of GPS receiver and satellite antennas. J Geod 81(12):781-798. https:// doi.org/10.1007/s00190-007-0148-y

Schmid R, Dach R, Collilieux X, Jäggi A, Schmitz M, Dilssner F (2016) Absolute IGS antenna phase center model igs08.atx: status and potential improvements. J Geod 90(4):343-364. https://doi.org/ 10.1007/s00190-015-0876-3

Villiger A, Dach LPA, Zimmermann F, Kuhlmann H, Jäggi A (2019) Consistency of antenna products in the MGEX environment. In: IGS Workshop 2018, Wuhan

Zhu YS, Massmann FH, Yu Y, Reigber C (2003) Satellite antenna phase center offsets and scale errors in GPS solutions. J Geod 76(11):668672. https://doi.org/10.1007/s00190-002-0294-1 
Open Access This chapter is licensed under the terms of the Creative Commons Attribution 4.0 International License (http://creativecommons. $\mathrm{org} /$ licenses/by/4.0/), which permits use, sharing, adaptation, distribution and reproduction in any medium or format, as long as you give appropriate credit to the original author(s) and the source, provide a link to the Creative Commons licence and indicate if changes were made.

The images or other third party material in this chapter are included in the chapter's Creative Commons licence, unless indicated otherwise in a credit line to the material. If material is not included in the chapter's Creative Commons licence and your intended use is not permitted by statutory regulation or exceeds the permitted use, you will need to obtain permission directly from the copyright holder. 